Original Article

\title{
Hearing Status in Children with Idiopathic Nephrotic Syndrome
}

\author{
Magid A.A. Ibrahim ${ }^{1}$, Ragia M. Said ${ }^{1}$, Dina A. Nabhan² \\ Department of Pediatrics, Faculty of Medicine, Ain Shams University. \\ General practitioner, Faculty of Medicine, Ain Shams University
}

\begin{abstract}
Background

The nephrotic syndrome is a glomerular disease, in which the glomerular capillary wall becomes no longer impermeable to proteins. It is characterized by nephrotic range proteinuria and the clinical findings associated with large urinary losses of protein: hypoalbuminemia, edema, and hyperlipidemia. The organs of the inner ear bear a physiological similarity to the kidney, both being concerned with maintaining the electrolyte concentration gradient. There is an association between renal and inner ear disorders, either genetically determined as in Alport syndrome and branchio-oto-renal syndrome or acquired as in acute kidney injury and chronic kidney disease.
\end{abstract}

\section{Aim of the Work}

To evaluate hearing status in children with idiopathic nephrotic syndrome.

\section{Patients and Methods}

This case-control study was conducted on 80 patients with nephrotic syndrome (for at least 12 months' duration) following up at Pediatric Nephrology Clinic, Children's Hospital, Ain Shams University and 20 (age and sex-matched) apparently healthy children as a control group Patients included were in remission or relapse and none had known ear disease or secondary nephrotic syndrome. Patients were subjected to thorough history taking and clinical examination. Corrected s. calcium, s. albumin and s. sodium was measured in all patients. Pure tone audiometry for all patients and controls was done to assess hearing status.

\section{Results}

We found that patients with hearing impairment had lower serum albumin and serum calcium. Presence of proteinuria and the use of cyclophosphamide was significantly more in patients with hearing impairment. We also found that sensorineural hearing loss group had lower serum calcium and as well as serum sodium compared to conductive hearing loss group, with no significant difference in serum albumin between the 2 subgroups. No significant difference was noted in hearing status among patients in remission and those in relapse

\section{Conclusion}

Biochemical changes in idiopathic nephrotic syndrome, especially electrolytes, may play a role in hearing impairment in those patients. Drugs- (maybe) perhaps through immunosuppression (and) as well as increasing infection incidence;may also contribute to hearing impairment especially conductive hearing loss.

Key words Hearing loss, Nephrotic Syndrome, Audiometry

\section{Correspondence}

Ragia M. Said

Department of Pediatrics, Faculty of Medicine, Ain Shams University Cairo, Egypt.

Email: ragia_marei@med.asu.edu.eg

\author{
geget : The Journal of the Egyptian Society of Pediatric Nephrology and Transplantation (ESPNT) \\ geget https://geget.journals.ekb.eg/ \\ Published by ESPNT http://espnt.net/ \\ Cohosted by Egyptian Knowledge Bank https://www.ekb.eg
}




\section{Introduction}

Nephrotic syndrome is primarily a pediatric disorder and is 15 times more common in children than adults. The incidence is 2-3/100,000 children per year; and the majority of affected children will have steroid-sensitive minimal change disease [1]. The characteristic features of nephrotic syndrome are heavy proteinuria ( $>3.5 \mathrm{~g} / 24 \mathrm{hr}$ in adults or $40 \mathrm{mg} / \mathrm{m} 2 / \mathrm{hr}$ in children),

hypoalbuminemia $(<2.5 \mathrm{~g} / \mathrm{dL})$, edema, and hyperlipidemia [1]. The organs of the inner ear and the kidney are physiologically similar [2]. An association exists between renal and inner ear disorders. This association may be genetically determined or acquired [3].

There is an intriguing connection between renal diseases and hearing disorders. The incidence of sensorineural hearing loss among patients with chronic renal failure is considerably higher than in the general population [4]. Vilayur et al. [5] report several physiological, ultrastructural and antigenic similarities between the kidney and the cochlea that strongly support the link between the hearing impairment and chronic kidney disease.

Children with idiopathic nephrotic syndrome have biochemical impairments which include hyponatremia, hypocalcemia. These biochemical abnormalities are known to cause hearing impairment [6]. The serum level of ionized normal in children with nephrotic syndrome, but it may decrease due to urinary loss of 25hydroxyvitamin D3 and inappropriate levels of calcitriol [7].

\section{Aim of the Work}

The aim of this study was to evaluate hearing status in children with idiopathic nephrotic syndrome.

\section{Patients and Methods}

PatientsThis case-control study was conducted at Pediatric Nephrology Clinic, Ain Shams University. It was conducted on 80 patients with idiopathic nephrotic syndrome (INS) (for at least 12 months) and 20 (age and sex-matched) apparently healthy children as a control group. Study Population: The study included children aged 5-16 years with INS. Children with secondary nephrotic syndrome, nephrotic syndrome with renal insufficiency, those with genetic basis of hearing impairment, or those having chronic suppurative otitis media (CSOM) in addition to those who received furosemide (on regular basis) were excluded from this study.

Patients were divided into 2 groups:

Group A (cases): 80 patients with idiopathic nephrotic syndrome. Group B (controls): 20 age and sex-matched healthy children. Then group A (cases) was subdivided into two subgroups regarding hearing status:

Subgroup A1: cases without hearing impairment. Subgroup A2: cases with hearing impairment. Cases with hearing impairment (group A2) were divided into two subsubgroups regarding the type of hearing impairment:

Sub-subgroup A2a: cases with sensorineural hearing loss. Subsubgroup A2b: cases with conductive hearing loss.
Methods: The approval of the local ethics committee of our hospital was obtained and informed consent was provided to all patients' parents/guardians.

\section{All the patients were subjected to the following}

Thorough history taking \& medical records revision laying stress on: History of hypertension \& drug history.

- Steroids intake duration and dose at the time of the study (where low dose is less than $1 \mathrm{mg} / \mathrm{kg} /$ day and high dose is more than $1 \mathrm{mg} / \mathrm{kg} / \mathrm{day}$ )

- Mendoza protocol

- Cyclophosphamide intake

- Cyclosporine A intake duration

$\square$ Thorough clinical examination to assess:

- $\quad$ Side effects of the drugs.

- $\quad$ Signs of remission or relapse.

Investigationns

- Complete urine analysis to assess proteinuria.

- $\quad$ Corrected serum calcium using the formula:

$[$ Corrected serum calcium $=$ serum calcium +0.8

(4 - Serum albumin)] [8].

- Serum sodium and serum albumin were done.

- Pure tone audiometry for all patients and controls to assess hearing status.

Hearing assessment by pure tone audiometery Equipment

1. Two channel audiometer, Interacustics model AC40.

2. Sound treated room I.A.C model 1602.

Method of hearing assessment by pure tone audiometry Full history taking. Otological examination was done and wax was removed from the external auditory canal of the patients. Basic audiological evaluation

(a) Pure tone audiometry including air and bone conduction (age-based hearing threshold determination).

(b) Speech audiometry including

- Speech Reception Threshold (S.R.T): using bisyllabic words for children.

- Speech Discrimination (S.D): using Arabic Phonetically-Balanced Kindergarten (PBKG) words.

The results of pure tone audiometry are recorded on a chart or a form called an audiogram.

\section{Statistical analysis}

Data management and analysis were performed using Statistical Package for Social Sciences (SPSS) vs. 21.

Numerical data were summarized using means and standard deviations or medians and ranges as appropriate. Categorical data were summarized as percentages. Comparisons between the 2 groups with respect to normally distributed numeric variables were done using the t-test. None normally distributed numeric variables were compared by Mann-Whitney test. For categorical variables, differences were analyzed with $\chi 2$ (chi-square) test and Fisher's exact test when appropriate.

All p-values were two-sided. P-values $<0.05$ were considered significant. 


\section{Results}

Our study included 80 nephrotic patients, 56 (70\%) were males and $24(30 \%)$ were females. $67(83.8 \%)$ were in remission and $13(16.2 \%)$ were in relapse. Only $29(36.2 \%)$ patients were hypertensive and 51(63.8\%) had normal blood pressure. 52(65\%) were on low dose steroids $(<1 \mathrm{mg} / \mathrm{Kg} /$ day $)$ and $28(35 \%)$ were on high dose steroids (> $1 \mathrm{mg} / \mathrm{Kg} /$ day) at the time of examination. $75(93.8 \%$ ) had steroid sensitive nephrotic syndrome(SSNS) [32 steroid dependent, 28 infrequent relapsers and 15 frequent relapsers] and 5(6.2\%) had steroid-resistant nephritic syndrome(SRNS).

Out of our 80 Nephrotic patients, 19(23.7\%) showed hearing impairment while 61(76.3\%) had normal hearing. Out of the 19 patients with hearing impairment, 9(45\%) had a sensorineural hearing loss while 10(55\%) had conductive hearing loss. These are shown in tables 1 to 6 and figure 1 to 2

Table 1: Cases and controls' important comparison points.

\begin{tabular}{|c|c|c|c|}
\hline & Cases & Controls & \multirow{2}{*}{$P$ value } \\
\hline & $\mathrm{n}=80(\%)$ & $\mathrm{n}=\mathbf{2 0}(\%)$ & \\
\hline \multicolumn{4}{|l|}{ Age (yrs) } \\
\hline Mean \pm SD & $9.7 \pm 3.0$ & $10.1 \pm 3.2$ & 0.622 \\
\hline \multicolumn{4}{|l|}{ Gender } \\
\hline Male & $56(70)$ & $13(65)$ & 0.863 \\
\hline Female & $24(30)$ & $7(35)$ & \\
\hline \multicolumn{4}{|l|}{ Serum Ca } \\
\hline Mean \pm SD & $8.9 \pm 0.5$ & $9.2 \pm 0.8$ & 0.023 \\
\hline \multicolumn{4}{|l|}{ Corrected S. Ca } \\
\hline Mean \pm SD & $9.4 \pm 0.5$ & $9.5 \pm 0.8$ & 0.937 \\
\hline \multicolumn{4}{|l|}{ S. Albumin } \\
\hline Mean \pm SD & $3.3 \pm 0.5$ & $3.7 \pm 0.3$ & 0.002 \\
\hline \multicolumn{4}{|l|}{ Serum Na level } \\
\hline Mean \pm SD & $135.3 \pm 3.9$ & $136.1 \pm 4.8$ & 0.417 \\
\hline
\end{tabular}


Table 2: Clinical and office testing points of comparison between cases with and without hearing impairment.

\begin{tabular}{|c|c|c|c|}
\hline & \multicolumn{2}{|c|}{ Hearing status } & \multirow{3}{*}{$P$ value } \\
\hline & \multirow{2}{*}{$\begin{array}{c}\text { Normal } \\
n=61\end{array}$} & \multirow{2}{*}{$\begin{array}{c}\text { Affected } \\
n=19\end{array}$} & \\
\hline & & & \\
\hline \multicolumn{4}{|l|}{ Age (yrs) } \\
\hline Mean \pm SD & $9.8 \pm 3.1$ & $9.6 \pm 2.4$ & 0.743 \\
\hline \multicolumn{4}{|l|}{ Gender } \\
\hline Male $(n=56)$ & $43(76.8)$ & $13(23.2)$ & 0.863 \\
\hline Female $(n=24)$ & $18(75.0)$ & $6(25.0)$ & \\
\hline \multicolumn{4}{|l|}{ Blood pressure } \\
\hline Normal $(\mathrm{n}=51)$ & $39(76.5)$ & $12(23.5)$ & 0.951 \\
\hline Hypertensive ( $\mathrm{n}=29$ ) & $22(75.9)$ & $7(24.1)$ & \\
\hline \multicolumn{4}{|l|}{ Disease status } \\
\hline Remission & $51(76.1)$ & $16(23.9)$ & 0.950 \\
\hline Relapse & 10(76.9) & $3(23.1)$ & \\
\hline \multicolumn{4}{|l|}{ Steroid dose } \\
\hline Low & $41(78.8)$ & $11(21.2)$ & 0.457 \\
\hline High & $20(71.4)$ & $8(28.6)$ & \\
\hline \multicolumn{4}{|l|}{ Duration of steroid intake } \\
\hline Median (range) & $3(1-9)$ & $2.8(1-5)$ & 0.091 \\
\hline \multicolumn{4}{|c|}{ Mendoza or Methylprednisolone intake } \\
\hline No & $52(75.4)$ & $17(24.6)$ & 0.640 \\
\hline Yes & $9(81.8)$ & $2(18.2)$ & \\
\hline \multicolumn{4}{|l|}{ Cyclosporine A duration } \\
\hline Median (range) & $24(17-24)$ & $17(2-24)$ & 0.196 \\
\hline \multicolumn{4}{|l|}{ Cyclophosphamide intake } \\
\hline No & $46(83.6)$ & $9(16.4)$ & 0.021 \\
\hline Yes & $15(60.0)$ & $10(40.0)$ & \\
\hline \multicolumn{4}{|l|}{ Proteinurea } \\
\hline Negative & $35(87.50)$ & $5(12.50)$ & 0.018 \\
\hline Positive & $26(65.00)$ & $14(35.00)$ & \\
\hline
\end{tabular}


Table 3: Laboratory points of comparison between cases with and without hearing impairment.

\begin{tabular}{|c|c|c|c|}
\hline & \multicolumn{2}{|c|}{ Hearing status } & \multirow{3}{*}{$P$ value } \\
\hline & Normal & Affected & \\
\hline & $n=61(\%)$ & $\mathrm{n}=19(\%)$ & \\
\hline \multicolumn{4}{|l|}{ Serum Ca } \\
\hline Mean \pm SD & $9.1 \pm 0.6$ & $8.4 \pm 0.6$ & $<0.001$ \\
\hline \multicolumn{4}{|c|}{ Corrected Serum Ca } \\
\hline Mean \pm SD & $9.5 \pm 0.6$ & $8.4 \pm 0.6$ & 0.014 \\
\hline $\begin{array}{l}\text { Serum Na } \\
\text { Mean } \pm S D\end{array}$ & $135.7 \pm 4.2$ & $134.5 \pm 4.1$ & 0.246 \\
\hline \multicolumn{4}{|c|}{ Serum Albumin } \\
\hline Mean \pm SD & $3.5 \pm 0.5$ & $3.1 \pm 0.6$ & 0.011 \\
\hline
\end{tabular}

Table 4: Clinical and office testing points of comparison between cases with SNHL and CHL.

\begin{tabular}{|c|c|c|c|}
\hline & \multicolumn{2}{|c|}{ Type of hearing impairment } & \multirow[b]{2}{*}{$\begin{array}{c}P \\
\text { value }\end{array}$} \\
\hline & n 9(\%) & n 10(\%) & \\
\hline \multicolumn{3}{|l|}{ Gender } & \multirow{3}{*}{0.628} \\
\hline Male & $7(53.80)$ & $6(46.20)$ & \\
\hline Female & $2(33.30)$ & $4(66.70)$ & \\
\hline \multicolumn{3}{|l|}{ Blood pressure } & \multirow{3}{*}{0.057} \\
\hline Normal & $8(66.70)$ & $4(33.30)$ & \\
\hline Hypertensive & $1(14.30)$ & $6(85.70)$ & \\
\hline \multicolumn{3}{|l|}{ Disease status } & \multirow{3}{*}{0.211} \\
\hline Remission & $9(56.30)$ & $7(43.80)$ & \\
\hline Relapse & $0(0.00)$ & $3(100.00)$ & \\
\hline \multicolumn{3}{|c|}{ Cyclophosphamide intake } & \multirow{3}{*}{0.001} \\
\hline No & $8(88.90)$ & $1(11.10)$ & \\
\hline Yes & $1(10.00)$ & $9(90.00)$ & \\
\hline \multicolumn{3}{|c|}{$\begin{array}{l}\text { Mendoza or Methylprednisolone } \\
\text { intake }\end{array}$} & \multirow{3}{*}{1.000} \\
\hline No & $8(47.1)$ & $9(52.9)$ & \\
\hline Yes & $1(50.0)$ & $1(50.0)$ & \\
\hline Steroid dose & $4(36.4)$ & $7(63.6)$ & \multirow{3}{*}{0.370} \\
\hline \multicolumn{3}{|l|}{ Low } & \\
\hline High & $5(62.5)$ & $3(37.5)$ & \\
\hline \multicolumn{3}{|l|}{ Proteinurea } & \multirow{3}{*}{0.028} \\
\hline Negative & $3(60.0)$ & $2(40.0)$ & \\
\hline Positive & $6(42.9)$ & $8(57.1)$ & \\
\hline
\end{tabular}


Table 5: Laboratory points of comparison between cases with SNHL and CHL.

\begin{tabular}{|c|c|c|c|}
\hline & \multicolumn{2}{|c|}{ Type of hearing loss } \\
\hline & Sensory neural & Conductive & Mean \pm SD \\
\hline Age (yrs) & Mean \pm SD & $9.6 \pm 2.6$ & 0.943 \\
\hline Serum Ca & $9.6 \pm 2.3$ & $8.8 \pm 0.6$ & 0.01 \\
\hline Corrected S. Ca & $8.1 \pm 0.4$ & $9.5 \pm 0.1$ & 0.001 \\
\hline S. Albumin & $8.7 \pm 0.5$ & $3.0 \pm 0.8$ & 0.432 \\
\hline Serum Na & $3.2 \pm 0.4$ & $136.4 \pm 4.3$ & 0.016 \\
\hline
\end{tabular}

Table 6: Duration of steriods and Cyclosporine A intake in SNHL and CHL cases.

\begin{tabular}{|c|c|c|c|c|c|c|c|c|}
\hline & \multicolumn{6}{|c|}{ Type of hearing loss } & \multirow{3}{*}{$\mathbf{Z}$} & \multirow{3}{*}{$P$ value } \\
\hline & \multicolumn{3}{|c|}{ Sensory neural } & \multicolumn{3}{|c|}{ Conductive } & & \\
\hline & Median & Min. & Max. & Median & Min. & Max. & & \\
\hline $\begin{array}{c}\text { Duration of } \\
\text { steriods intake (years) }\end{array}$ & 2 & 1 & 2 & 4.5 & 2 & 5 & -3.398 & 0.001 \\
\hline $\begin{array}{c}\text { Duration of } \\
\text { Cyclosporine A intake } \\
\text { (months) }\end{array}$ & 17 & 2 & 24 & 24 & 2 & 24 & -1.127 & 0.261 \\
\hline
\end{tabular}

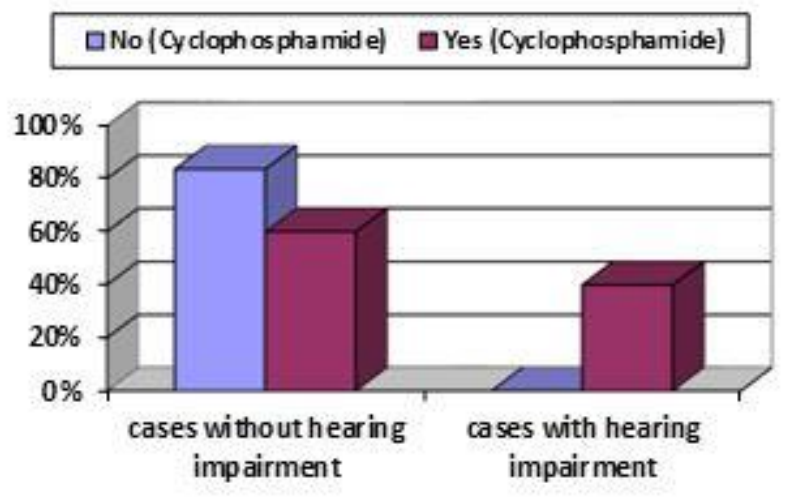

Figure 1: Cyclophosphamide intake in cases with or without hearing impairment 


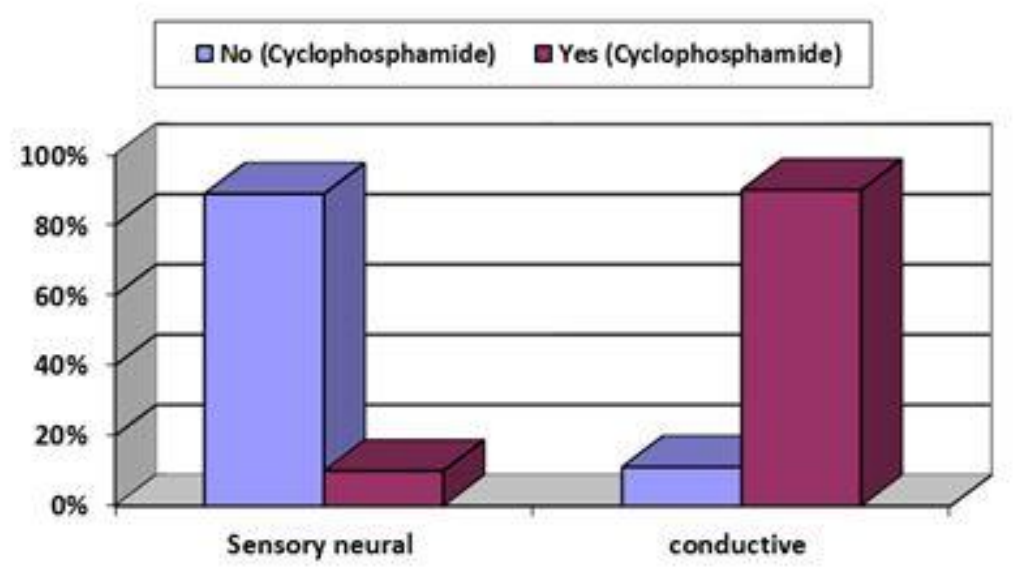

Figure 2: Cyclophoshamide intake in SNHL and CHL cases.

\section{Discussion}

The current study revealed that serum calcium (but not corrected calcium) and albumin levels were lower in cases than in controls $(\mathrm{P}<0.05)$ which is statistically significant, though most of the patients at our study were in remission $(83.3 \%)$. There was no statistically significant difference between both groups as regards serum sodium levels. Similar results were published by Saha et al. [6] who reported

that children with Nephrotic syndrome had lower

serum protein, serum albumin and serum calcium levels than controls and there was no statistically significant difference in serum sodium.

As regards study showed a statistically serum $\mathrm{Ca}$ and corrected hearing affection, our significant lower impairment than in cases without hearing impairment $(\mathrm{P}<0.05)$.There was no statistically significant difference as regards serum sodium in both groups. This is consistent with both Saha et al. [6] and Liang et al. [9] and El Mashad et al [10] studies. At Saha et al. study, children with nephrosis and hearing impairment had low corrected serum calcium levels $\quad(\mathrm{P}<0.04)$. Liang et al. [9] showed that hypocalcemia significantly reduces the pass $r$ ateof transient evoked otoacoustic emission (TEOAE) in newborns. El Mashad et al [1] concluded that children with nephrotic syndrome are at risk of sensorineural hearing impairment. The hazards associated with this impairment included hypoalbuminemia and hypocalcemia.

As regards the type of hearing loss, we found that serum calcium and corrected serum calcium were significantly lower in cases with sensorineural hearing loss when compared to those with conductive hearing loss $(\mathrm{P}<0.05)$ showing that hypocalcemia might be a risk factor for sensorineural hearing loss. These results are consistent with those of Saha et al [6]. It is possible that the difference in compliance with calcium su pplementation might have influenced the serum calcium levels in our patients. It is particularly recommended to give $\mathrm{Ca}$ and Vit D supplementations to SRNS [11].
Orendorz et al. [7] did a case-control study that evaluated hearing status in 28 children with idiopathic nephrotic syndrome and 28 healthy children by pure tone audiometry. It was found that hearing tests carried out in relapse and remission showed the presence of partially reversible disorder in remission at the level of the inner ear and auditory pathway. During a relapse, characteristic biochemical and electrolyte disturbances, including significantly lower values of total serum protein, albumin, and calcium levels were found. The concentration of serum sodium was normal during remission and relapse. There was improvement during remission in the majority of hearing parameters which indicates their relationship with the biochemical and electrolyte disturbances that occur in nephrotic syndrome [7].

At the same time at several frequencies (1000-4000 $\mathrm{Hz}$ ), hearing acuity improvement was significantly associated with higher concentrations of serum calcium. Calcium synaptic neurotransmission affects membrane excitability and is a major factor affecting the rate of conduction through the nerve and plays a major role in the process of depolarization of hair cells [12].

Calcium is involved in the basic

organization of biological systems and physiochemical reactions of cellular function. It also plays a role in cellular adhesion, regulation of membrane permeability and control of neuromuscular excitability. ATPase activity which maintains the differential biochemical integrity of the inner ear fluid is calciumdependent. A deficiency of ionized calcium adversely affects the transmission of nerve action potential generated by cochlea by inhibiting the release of neurotransmitter substance at the neural synapses and impairing neural excitability. Brookes et al. [13] reported that vitamin D defici ency and the resultant hypocalcemia may result in cochlear deafness. Using a rat mo del, Ikeda et al. [14] observed a significant

decrease in perilymphatic calcium ion concentration secondary to low serum calcium level. These authors

suggested that a decrease calcium level of the perilymphatic fluid may decrease 
calcium ion concentration in the endolymphatic fluid and hence acoustic transduction. These results indicate that hypocalcemia itself alters the calcium level of the inner ear fluid and causes cochlear dysfunction.

Concerning the serum $\mathrm{Na}$ level, it was normal in all cases of our study either with or without hearing impairment. Consequently, there was no statistically significant difference at serum $\mathrm{Na}$ levels on comparing the two groups ( $\mathrm{P}$ value $>0.05$ ). While on comparing serum $\mathrm{Na}$ level in cases with conductive hearing loss and in cases with sensorineural hearing loss, it was found that serum $\mathrm{Na}$ was significantly lower in cases with sensorineural hearing loss than in cases with conductive hearing loss ( $\mathrm{P}$ value $<0.005)$. This illustrates that hyponatremia may be a risk factor for sensorineural hearing loss. Meena et al. [4] assessed hearing loss in patients with chronic renal failure. They found that patients with SNHL over $70 \mathrm{db}$ had significantly lower serum sodium and this signifies the role of electrolyte disarray in causing SNHL. On the other hand, Liang et al [9] found no significant effect in cases with hyponatremia.

Regarding proteinurea and serum albumin, cases with hearing impairment had protienura and lower serum albumin when compared with cases without hearing impairment $(\mathrm{P}<0.05)$. Our study suggests that proteinurea and therefore hypoalbuminemia may be risk factors for hearing impairment. Hypoalbuminemia decrease plasma oncotic pressure which leads to generalized edema by the movement of water from the blood into the interstitial space. Similar changes may affect inner ear causing hearing impairment [15].

As regards the disease status, we found no significant difference in hearing status between patients in relapse and those in remission. Saha et al [6] found the same by comparing the results of audiometry of the same patient once during remission and once during relapse. Also, Bayazitet al. (2005) [16] assessed the influence of relapse \& remission periods on hearing in children with minimal change nephrotic syndrome. They found that MCNS in childhood is not associated with an alteration of hearing status in remission and relapse periods of the disease. On the contrary, Orendorz et al [7] found that hearing acuity was lower in patients in relapse than in patients in remission, other studies found the same. [10], [17].

As regards the effect of treatment on hearing, it was found that Cyclophosphamide intake was significantly higher in patients with conductive hearing loss than those with

sensorineural hearing loss $(\mathrm{P}<0.05)$. The mechanism by which Cyclophosphamide affects hearing is not clear and may need further studies. It caused conductive hearing loss which may be attributed to recurrent lowgrade ear infections that are caused by immunesuppression.

At our study, it was noted that a longer duration of steroid intake was associated with conductive hearing loss which may be explained by immune suppression caused by steroid which leads to repeated infections. Duration of cyclosporine A (CsA) treatment seems to play no role in hearing impairment. There was no significant difference in it between cases with or without hearing impairment as well as between SNHL and CHL cases same was found by Kasap et al. [18]. They found that CsA is not responsible for permanent sensorineural hearing loss in children with NS.

\section{Conclusion}

Hypocalcemia, hypoalbuminemia, and hyponatremia seems to affect hearing and should be followed up in childhood nephrotic syndrome.

Immunosuppressive drugs as Cyclophosphamide and steroids for a long period may also be risk factors for conductive hearing loss.

\section{References}

1. Vogt B A, and Avner E D: conditions particularly associated with proteinurea; In KleigmanR and Nelson WE (eds) Nelson textbook of pediatriacs, 18th edition Saunders, Elsevier Philadelphia 2007; PP: 507-515.

2. Aryan CE, Clapp WL, Redman RS and Dharnidharka VR.: Hearing loss in renal failure differential diagnosis. Am J Kidney Dis. 2006; 47(3):553-558.

3. Kumar S, Chakravarti A, Sahni J, Dubey NK and Rathore R.: Auditory brain stem evoked response (ABR) study in patients with pediatric chronic renal failure undergoing peritoneal dialysis.

Indian J Otol. 2004; 9:24-27.

4. Meena RS, Aseri Y, Singh BK and Verma PC: Hearing Loss in Patients of Chronic Renal Failure: A Study of 100 Cases.

Indian J Otolaryngol Head Neck Surg 2012; 64: 356-359. 5. Vilayur E, Gopinath B, Harris DC, Burlutsky G, McMahon CM and Mitchell P: The association between reduced GFR and hearing loss: a cross-sectional population-based study.

Am J Kidney Dis. 2010; 56(4):661-669.

6. Saha A, Gupta V, Kapoor K, Dubey NK, Lal P, Sidhu TS, Batra VV, Upadhyay AD: Hearing status in children with frequently relapsing and steroid resistant nephrotic syndrome.

Int J Pediatr Otorhinolaryngol. 2013; 77(7):1072-6.

7. Orendorz-Frqczkowska K, Medynska A, Jablonka A, and Gawron W: Hearing organ function in children with nephrotic syndrome in course of primary glomerulopathy. Otolaryngologia Polska 2008; 12:182-187.

8. Bushinsky DA and Monk RD: Electrolyte quintet: calcium. Lancet 1998; 352:306-311.

9. Liang C, Hong Q, Jiang TT, Gao Y, Yao XF, Luo XX , Zhuo XH, Shinn JB, Jones and Lu GJ: The effects and outcomes of electrolyte disturbances and asphyxia on newborns hearing. Indian $\mathbf{J}$ Otolaryngol Head Neck Surg. 2012; 64(4):356-359.

10. El Mashad, G.M., Abo El Fotoh W.M.M., Zein El Abedein A.M., Abd El Sadek F.A.E.R.: Biochemical alteration in children with idiopathic nephrotic syndrome associated with an increased risk of sensorineural hearing loss; additional insights in cochlear renal relationship. International Journal of Pediatric Otorhinolaryngology 2017; 97: 206-210.

11. Indian Pediatrics Nephrology Group and Indian Academy of Pediatrics: Management of steroid-sensitive nephrotic syndrome: Revised guidelines.

Indian Pediatr. 2008;45:203-214. 
12. Sliwinska-Kowalska $M$ and Orlowski T: Primary glomerulonephritis. In: Orlowski $\mathrm{T}$ editors. Kidney disease. Ed. IV. Warsaw: PZWL 2000; p 367-392.

13. Brookes GB: Vitamin D deficiency and deafness: 1984 update. Am J Otol. 1985; 6:102-107.

14. Ikeda K, Kusakari J, Kobayashi T, and Saito Y: The effect of vitamin $\mathrm{D}$ deficiency on the cochlear potentials and the perilymphatic ionized calcium concentration of rats. Acta Otolaryngol Suppl. 1987; 435:64-72.

15. Ray EC, Rondon-Berrios H, and

Boyd CR, Kleyman

TR.: Sodium retention and volume expansion in nephrotic syndrome:

implications for hypertension. Advances in chronic kidney disease. 2015; 22(3):179-84.
16. Bayazit YA, Balat A, Pakir HI, and Kanlikama M: Influence of relapse and periods on hearing status in children with Güler E, change nephrotic syndrome.

Rev Laryngol Otol Rhinol. 2005; 126(3):171-1

17. Mahfouz Nermine N., El-Shabrawy Marwa M., Ghobrial Emad E.: Hearing status in Egyptian children with nephrotic syndrome.

Medical Research Journal 2016; 15(1): 1-7

18. Kasap-Demir B., Özmen D., Kırkım G., Doğan E., Soylu A., Şerbetçioğlu B., Kavukçu S.: Cyclosporine causes no hearing defect in pediatric patients with nephrotic syndrome. International Journal of Audiology2017; 56(9):701-705.

\section{Declaration}

\section{Ethics approval and consent to participate}

This study protocol and the consents were approved and deemed sufficient by Ethical Committee of Pediatric Department, Faculty of Medicine, Ain Shams University. And informed written consent was obtained in every case from their legal guardians.

Funding: The authors declare that they didn't receive any financial support from agencies or others.

Conflict of interest: No

\section{Acknowledgements}

We would like to thank all patients and their family members for their valuable contributions to the study. 